\title{
An Integrated Multicriteria Decision-Making Approach to Evaluate Traveler Modes' Priority: An Application to Peshawar, Pakistan
}

\author{
Asim Farooq $\mathbb{D}^{1},{ }^{1}$ Svetla Stoilova, ${ }^{2}$ Firoz Ahmad $\left(\mathbb{D},{ }^{3}\right.$ M. Alam, ${ }^{4}$ Hassan Nassar, ${ }^{5}$ \\ Tanveer Qaiser, ${ }^{5}$ Kamran Iqbal, ${ }^{6}$ Abdul Qadir, ${ }^{7}$ and Mahmood Ahmad $\oplus^{8}$ \\ ${ }^{1}$ Department of Transportation Engineering, Pak-Austria Fachhochschule Institute of Applied Sciences and Technology, \\ Haripur, Pakistan \\ ${ }^{2}$ Department of Transportation, Technical University-Sofia, Sofia, Bulgaria \\ ${ }^{3}$ Vindhyan Ecology and Natural History Foundation, Mirzapur, Uttar Pradesh, India \\ ${ }^{4}$ Department of Civil Engineering, University of Engineering \& Technology, Mardan, Pakistan \\ ${ }^{5}$ Department of Civil Engineering, CECOS University of IT \& Emerging Sciences, Peshawar, Pakistan \\ ${ }^{6}$ Beijing University of Technology, Beijing, China \\ ${ }^{7}$ Department of Geography, Punjab University, Chandigarh, India \\ ${ }^{8}$ Department of Civil Engineering, University of Engineering and Technology, Peshawar (Bannu Campus), Bannu, Pakistan
}

Correspondence should be addressed to Asim Farooq; asimfarooq1234@gmail.com

Received 12 February 2021; Revised 2 April 2021; Accepted 9 April 2021; Published 22 April 2021

Academic Editor: Anna Granà

Copyright (C) 2021 Asim Farooq et al. This is an open access article distributed under the Creative Commons Attribution License, which permits unrestricted use, distribution, and reproduction in any medium, provided the original work is properly cited.

The transport planning is essential to meeting passengers' needs for fast, safe, and reliable transport. The research goals of this study are to determine the most suitable mode of transport between predetermined alternatives according the criteria related to the transport planning. The research method combines GIS analysis, SWOT analysis, BEM method, and PROMETHEE II method in an integrated approach for decision-making. The methodology is applied to the city of Peshawar city. It includes six steps. First, a passenger questionnaire is used to establish passenger preferences when making a trip in the city. Secondly, alternative modes of urban transportation are defined. In the case of Peshawar, the following alternatives are considered: a new BRT service, BRT with five additional stops, old bus service, wagon, carpooling, and Careem/Uber. Thirdly, there is GIS analysis to investigate the stops of the BRT alternative transportation. GIS and satellite analysis have been completed for each stop. Fourthly, criteria for the assessment of urban transport modes are determined based on SWOT analysis. A total of twenty four subcriteria are proposed. Fifthly, the best-worst method (BWM) which is based on linear programming method is applied to determine the weightings that should be given to the main criteria and subcriteria. Sixthly, alternative modes of transportation are ranked by applying preference ranking organization method for enrichment evaluations' (PROMETHEE II) method. The results show that the main important criteria greater than 5\% are small movement interval: S4 (6\%), security: S7 (13\%), reliability: S8 (8\%), accessibility:O1 (15\%), possibility of special services: O2 (5\%), possibility of including insurance in the travel tariff: O3 (8\%), possibility of the modernization of the infrastructure: $\mathrm{O} 4$ (7\%), and environmental pollution: T3 (5\%). The implications of this study propose a BRT service with five additional stops is the best urban transport plan for Peshawar. The originality of this research consists in integration of a strategic planning technique SWOT analysis, GIS analysis, and multicriteria analysis in complete methodology to evaluate traveler's modes priority. The methodology used in this research can be applied to evaluate different transport alternatives for transport networks worldwide. 


\section{Introduction}

Transportation planning is essential for meeting passengers' needs for fast, safe, and reliable transport. It is necessary to provide good public transport infrastructure for comfortable journeys, punctuality, and safety. The choice of efficient transport depends on economic, technological, social, and other factors. Therefore, the efficiency of different modes of urban transport should be investigated taking these various factors into account. The purpose of this study is to evaluate different modes of urban transport based on passengers' preferences using research based on a questionnaire and applying multicriteria analysis, SWOT, and GIS analysis.

The hypothesis of this research is that the passenger preferences established by survey, the strategic planning technique criteria to identify strengths, weaknesses, opportunities, and threats related to transport process, and the multicriteria methods have to be taken into account to evaluate traveler modes priority in urban transport. The research questions are addressed to the following issues: how the decision maker to select the appropriate alternative; how to increase the adequacy of the results.

The methodology is applied to the city of Peshawar.

The urbanization leads to increase in traffic congestion throughout the world, and it is a fact that expansion in road capacity cannot keep pace with the rapid growth in travel demand resulting from increases in population and vehicle ownership. Hence, some form of regulatory control is necessary to curtail traffic congestion. In general, whenever road capacity is increased in urban areas, traffic grows rapidly due to the release of previously suppressed trips which are regenerated because motorists now choose to use private transport at the desired time of travel. The standard response to solving traffic congestion in the long run is by increasing road capacity, but the problem is still unsolved [1]. The expansion of roads will severely affect the travel reliability, reduce the level of comfort due to congestion, and reduce safety. Developing countries such as Pakistan are growing moderately, and many people around the country are migrating towards cites. Accommodating the increasing demand of the people is quite challenging for urban planners and transportation expert. The rapid raising of urban population upsurges the attraction of car ownership, while the travel mode is shifting towards collective and sustainable modes [2].

Peshawar is the provisional capital of Khyber Pakhtunkhwa, with a population of 2 billion, and 6th largest city of the country. Due to the safety condition across the region, the central city of the province has recently seen surge almost 2.5 times in it migrate population, as compare to 2000, partially due to migration from the remote regions. The transportation department of the city is in fragile mode, while the population already menaces the tough challenges to the city administration [3]. Due to lack of planning development, the city is bleeding from many serious issues such as congestion, traffic delays, longer travel time, and dependency on private vehicle. Road blockage due to protocol is a daily routine for the city inhabitants, which destroy the sake to the historical city. In the current situation, urban transport is still served by obsolete modes of transport, such as those with little transport capacity, which cause congestion in the big city and pollute the environment. The motivation of this research is to prove that the Peshawar city has a need to reorganize public transport by introducing modern fast and convenient modes transport, such as BRT, the introduction of new stops for BRT to meet the needs of transport services.

The questions put during the survey were designed to evaluate the following:

(i) How did passengers' rate the BRT service with regards to reliability, comfort, and safety and what did they regard as an affordable price per stop?

(ii) Did different categories of people in Peshawar have different preferences?

(iii) Are people willing to pay extra, and for what? With regard to where the buses stop, what are the concerns of homeowners with respect to privacy and investors with respect to their businesses? (Peshawar is one of the leading cultural provinces of Pakistan-even religion takes second place to cultural norms).

Multicriteria analysis is an appropriate method for taking decisions in transport planning. The present research proposes an integrated approach based on a questionnaire completed by passengers, multicriteria analysis, SWOT analysis, and GIS analysis for selection of the best transport mode for urban passenger transport. The GIS analysis is applied to investigate the stops of the BRT service. The SWOT analysis defines the criteria into the SWOT group's strengths, weaknesses, opportunities, and threats related to different modes of transport in the city. The multicriteria approach is used to determine the weight that should be given to particular criteria and how to rank the alternatives. The benefits of combination of GIS analysis, SWOT analysis, and BWM method consists in taking into account criteria for strategic planning, increasing the accuracy in defining the criteria through GIS analysis, and selecting the most appropriate alternative by taking into account a set of criteria affecting the transport process.

The study is focused on travelers' preferences among different transportation systems, their attitudes to existing services, to the newly built Bus Rapid transit (BRT) and carsharing (carpool) and (Careem). It aims to investigate the punctuality, comfort, and safety of these services drawing on the results of a questionnaire devised for that purpose.

It should be noted that some authors only define the criteria in SWOT groups, while other authors additionally determine the weights of the criteria using multicriteria analysis methods. The novel contribution of this paper is the elaboration of a methodology for assessing of transport modes in urban area taking into account the SWOT criteria and multicriteria analysis.

The structure of the paper is as follows. Section 2 presents a literature review. Section 3 constructs a research methodology. Section 4 presents the results and discussion. Finally, the conclusions are presented. 


\section{Literature Review}

Different multicriteria methods and criteria are used to choose the mode for transportation. Different studies have been conducted to analyze travel time reliability [4] comfort, safety, and services [1]. Many studies have considered safety $[5,6]$ to be the most important parameter for public transportation in respect of willingness to travel. Others have considered comfort [7].

Some new studies addressing the most suitable mode of transport and multicriteria methods are elaborated by [8-10]. Laberinti et al. [8] elaborated a novel approach for solving fully intuitionistic fuzzy multiobjective fractional transportation problem. In the proposed model, because of the change of market policies, the authors used trapezoidal intuitionistic fuzzy numbers for the transportation charge, the shipped quantity, the supply, and the demand parameters. Mokhtari and Hasani [10] presented a multiobjective optimization model for a cleaner production-transportation planning problem in manufacturing plants. The fuzzy goal programming has been adopted and heuristic algorithms were designed. The model allows to determine cost-effective production level, inventory level, back-order level, overtime and subcontract productions, and transportation and production modes, so as to reduce green-house gas emissions, industrial wastes, noise pollutions, workers' damage, and energy consumption. Koohathongsumrit and Meethom [9] proposed a novel integrated framework of fuzzy risk assessment model, data envelopment analysis (DEA), and multiple criteria decision-making approaches for route selection in multimodal transportation networks. The fuzzy analytic hierarchy process has been used to determine the weights of three decision criteria of transportation cost, transportation time, and overall risk magnitude. A zero-one goal programming model was used to select the most appropriate multimodal route. The integrated approach has been tested for multimodal freight transportation route selection between Thailand and Cambodia.

The best-worst method (BWM) is a multicriteria decision-making method developed by $[11,12]$. It is used to determine the respective weights of predefined criteria and to evaluate alternatives to these criteria. BWM uses the most important criterion called best, and the criterion with the opposite role, called worst, is identified by the decision maker to make a pairwise comparison of the decision criteria. The method is based on linear programming to determine the criteria weights. BWM is used in various decision-making areas such as logistics [13-15], economics $[16]$, and transport and engineering $[17,18]$ due to its easy applicability and reliable results.

SWOT analysis as a strategic planning technique is used to determine strengths, weaknesses, opportunities, and threats. Furthermore, a combination of both methods-SWOT analysis and AHP-has been used in other research fields and decision-making activities $[19,20]$. The PROMERHEE II method is one of the most frequently used multicriteria methods to rank alternatives [21, 22]. This research adopts a combination of methodologies such as GIS, BWM, PROMERHEE, and SWOT.
The combination of GIS and AHP has been used to analyze transportation planning, and the connectivity of the megacities model has been developed and analyzed [1]. Combinations of GIS, AHP, and BWM have also been used in the field of strategy and management and susceptibility $[23,24]$. Combinations of AHP and BWM have been used by many researchers to address different applied research problems [23-25]. Different types of methodology have been used to address different transportation issues such as MCA with DEMATEL [26].

\section{Methodology}

This study presents a new hybrid methodology based on the combination of questionnaire method, GIS analysis, SWOT analysis, and BWM and PROMETHEE methods for selecting the most appropriate mode of urban transportation for passengers.

The methodology includes the following steps:

(i) Step 1: conducting a passenger survey using a questionnaire to establish passengers' preferences when making a trip to the city.

(ii) Step 2: selection of alternative modes of urban transportation.

(iii) Step 3. GIS analysis for investigating the BRT alternative stops.

(iv) Step 4: definition of quantitative and qualitative criteria for the assessment of these alternatives. This step of the methodology uses SWOT analysis as a strategic planning technique to identify strengths, weaknesses, opportunities, and threats related to a different mode of transport in the city. The subcriteria for each main criterion of a SWOT group are defined so as to evaluate the alternatives.

(v) Step 5: determination of the weight to be given to each criterion by applying the BWM method.

(vi) Step 6: ranking alternative modes of transportation by applying the PROMETHEE II method.

\subsection{Conducting the Passenger Survey Using a Questionnaire in Order to Establish Passengers' Preferences When Making a Trip in the City}

(i) The transportation network of a country contributes to the economy and stability of the country and increases travel options for its people and goods. In Pakistan, there is a dire need of transportation networks. So, transportation planning must be robust. In Peshawar, no model public travel mode exists. Most of the public transportation is monitored, supervised, and run by private transporters. Peshawar public transportation faces a heap of problems such as unreliability, no fixed stops, no time table, high floor mode, old vehicles, and low travelling speed. 
(ii) The questionnaire was devised to investigate demand for transport in general and the requirements of passengers in particular. The following target groups were included in the survey: the business community, labourers, engineers, doctors, teachers, and students. The results for all the target groups are presented in Table 1 .

3.2. Determining Alternative Modes of Transportation. Five different types of public travel options exist in Peshawar: old buses (racket buses, wagon, carpooling, rickshaws (tri-wheeler), Careem/Uber, and BRT [27].

Along the case study route, there are only 5 options, while rickshaws (tri-wheeler) operate outside the city, which is why we did not consider that in this research.

The second step includes the following alternative modes of transportation for Peshawar City:

The service by old bus (racket buses) is the worst mode of travel used by people who do not have other options. It provides accessibility to all corners of the city of Peshawar [27], but it is the least popular mode of transport according to the questionnaire, and usually due to the traffic violations by wagons or old buses, there is a gridlock in the city [28]. The wagon service is the second most used mode of travel in Peshawar city [29] and is considered better than the old bus service (racket system). Carpooling is a local service, which operates on specified routes, where 3 to 4 passengers share their ride. The Careem/Uber service is a modern way to travel, which can be used from the android set, and is considered more attractive among those completing the questionnaire, as the prices are almost the same as a local taxi, and it offers more security, reliability, and privacy [30]. The BRT service is the first sustainable transport project in Peshawar. It facilitates the travel of around half a million people in the city and is especially comfortable, safe, affordable, and environmentally friendly [24].

3.3. GIS Analysis. The GIS analysis was undertaken to check the planning of stations according to the settlement and density of the population along with the main road network. The 100 meter regular grid was generated within a $3 \mathrm{~km}$ buffer area of BRT line to analyze the residential population. Satellite image analysis was carried out in whole buffer area around each station to determine the settlement, population density, settlement hotspots, road density function, and priority graph [31-33]. Studies use GIS as the best model for transportation networking, accessibility analysis, and settlement density $[34,35]$, spatial distribution and settlement analytics [36], and the relation of transportation to the built environment [37]. Furthermore, GIS allows the researcher to analyze the spatial and temporal distribution with respect to land cover and population [38] and stilt relation with respect to population and public transportation riders [39] and analyze social pattern [40].
3.4. SWOT Analysis. In the fourth step, SWOT analysis is applied to define the criteria for assessing modes of transportation. The criteria were chosen based on questionnaire research and additional criteria that are important for transportation such as security, reliability, environmental pollution, and noise. These criteria are included as subcriteria in the following SWOT main groups: strengths, weaknesses, opportunities, and threats. The strengths and weaknesses are internal criteria, while the opportunities and threats are external criteria for urban transport mode selection.

The subcriteria for internal strength factors are as follows.

Internal strengths (IS):

(S1) Dedicated infrastructure, coeff.

(S2) Fixed stops, coeff.

(S3) Average distance between stops, $\mathrm{m}$

(S3) Small movement interval, min

(S5) Stops near residential districts, coeff.

(S6) Stops near the central business district, coeff.

(S7) Security, coeff.

(S8) Reliability, coeff.

The subcriteria for internal weakness factors are as follows.

Internal weakness (IW):

(W1) High cost of travel for one person, \$

(W2) Lack of connectivity to urban infrastructure, coeff.

(W3) Small number of seats in one vehicle, number

(W4) Low operating speed, $\mathrm{km} / \mathrm{h}$

(W5) Long time for travel, min

(W6) Small comfort, coeff.

The subcriteria for external opportunities factors are as follows.

External opportunities (EO):

(O1) Accessibility, coeff.

(O2) Possibility of special services, coeff.

(O3) Possibility of the inclusion of insurance in the travel tariff, coeff.

(O4) Possibility of modernization of the infrastructure, coeff.

The subcriteria for external threats factors are as follows.

External threats (ET):

(T1) Increase in car traffic, coeff.

(T2) Possibilities of traffic congestion, coeff.

(T3) Environmental pollution, coeff.

(T4) Noise, coeff.

(T5) Dependence on mineral oil or imported gas, coeff.

(T6) Increasing fuel costs, coeff.

The criteria S1, S2, S5, S6, S7, S8, W2, W6, O1, O2, O3, O4, T1, T2, T3, T4, T5, and T6 can take values of 0 or 1 . The 


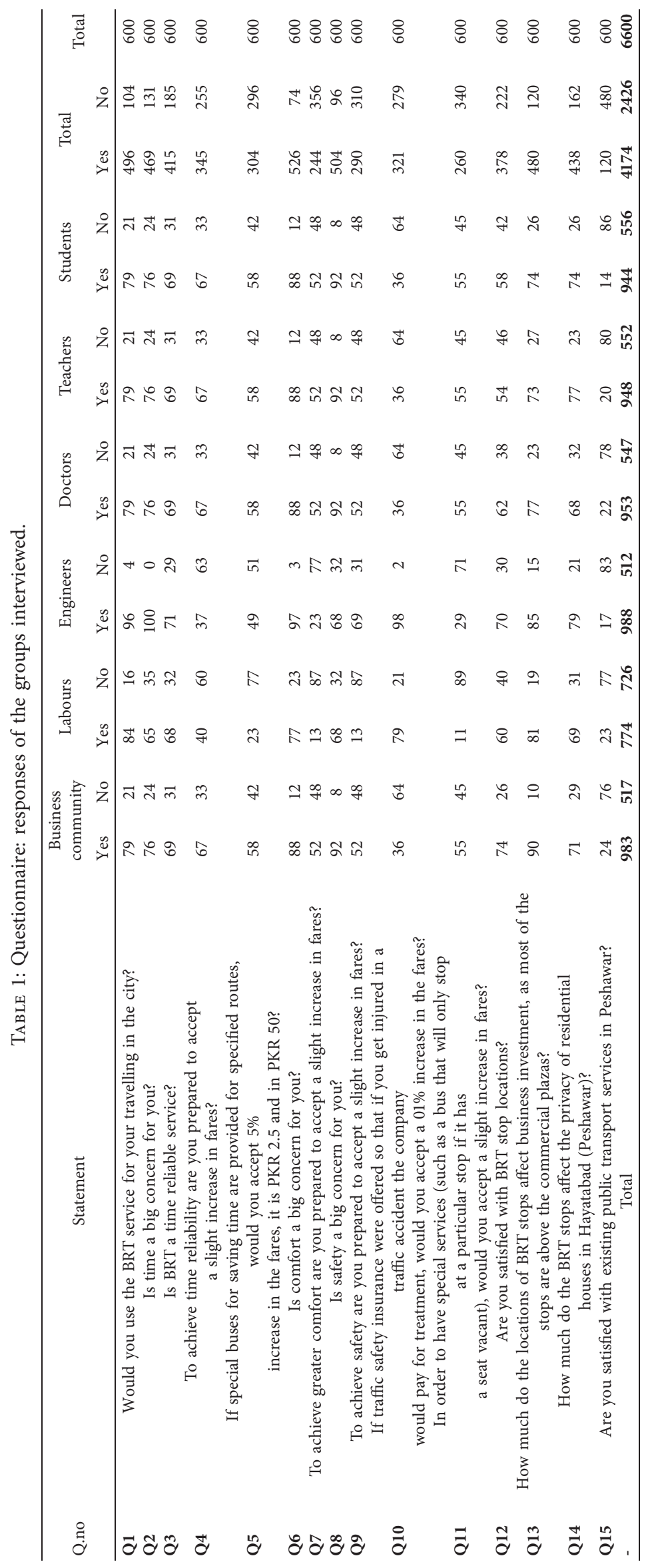


value of a criterion is 1 if the answer is "yes" and the value is 0 otherwise.

3.5. Best-Worst Method (BWM). The fifth step is designed to decide how much weight to give to the different criteria. The study proposes the BWM method for this purpose. The methodology of BWM consists of the following steps $[11,12]$ :

(i) Step 1: determination of the criteria for decision-making

(ii) Step 2: determination of best and worst criteria.

In this step, the expert identifies from his point of view, based on his competence, the most important, i.e., best criterion, and least important, i.e., worst criterion.

(iii) Step 3: determination of which criterion should be preferred over all the others.

Table 2 presents the linguistic scale for pairwise comparison for BWM.

The scale of pairwise comparison uses numbers between 1 and 9 , where 1 shows that the compared criteria have the same importance, while 9 presents extreme importance.

The results best-to-others vector is as follows:

$$
A_{B}=\left(a_{B 1}, a_{B 2}, \ldots, a_{B n}\right),
$$

where $a_{B j}$ is preference of the best criterion $B$ over criterion $j$. In this case, $a_{B B}=1$.

(iv) Step 4: determination of the order of preference of each criterion.

For this purpose, the 1-10 scale of pairwise comparison is used again. The resulting Others-to-Worst vector is as follows:

$$
A_{w}=\left(a_{1 w}, a_{2 w}, \ldots, a_{n w}\right)^{T},
$$

where $a_{j W}$ is preference of the criterion $j$ over the worst criterion $W$. In this case, $a_{W W} a_{W W}=1$.

(v) Step 5 : determination of the optimal weights.

For this purpose, the following $\min _{\max }$ model is formulated:

$$
\begin{gathered}
\min \max _{j}\left\{\left|w_{B}-a_{B j} \cdot w_{j}\right|,\left|w_{j}-a_{j W} \cdot w_{W}\right|\right\}, \\
\sum_{j=1}^{n} w_{j}=1, \\
w_{j} \geq 0, \quad \text { for all } j=1, \ldots, n,
\end{gathered}
$$

where $w_{j}$ denotes weights of criteria, $j=1, \ldots, n$.

The model given by formulas (3)-(5) can be solved by transferring it to a linear optimization model as follows:
TABLE 2: Linguistic scale for pairwise comparison for BWM.

\begin{tabular}{lc}
\hline Scale & Score \\
\hline Equally important & 1 \\
Equal to moderately more important & 2 \\
Moderately more important & 3 \\
Moderately to strongly important & 4 \\
Strongly more important & 5 \\
Strongly to very strongly important & 6 \\
Very strongly more important & 7 \\
Very strongly to extremely more important & 8 \\
Extremely more important & 9 \\
\hline
\end{tabular}

$$
\begin{gathered}
\min \xi^{L}, \\
\left|w_{B}-a_{B j} \cdot w_{j}\right| \leq \xi^{L}, \quad \text { for all } j, \\
\left|w_{j}-a_{j W} \cdot w_{W}\right| \leq \xi^{L}, \quad \text { for all } j, \\
\sum_{j=1}^{n} w_{j}, \\
w_{j} \geq 0, \quad \text { for all } j=1, \ldots, n .
\end{gathered}
$$

The model given by formulas (6)-(10) is linear and has a unique solution. The optimal weights $\left(w_{1}^{*}, w_{2}^{*}, \ldots, w_{n}^{*}\right)$ and optimal value $\xi^{*}$ are obtained. The value $\xi^{*}$ is defined as the consistency ratio of system. A value close to zero is desired for consistency.

The received results of the weights can be used to determine the score of the alternatives on the different criteria.

3.6. Ranking the Alternative Modes of Transportation by Applying the PROMETHEE II Method. The weighting placed on each criterion determined by BWM is used in the PROMETHEE II method to evaluate the alternatives. This method applies a comparison of pair per pair of possible decisions along each criterion. The type of optimization of criteria has to be set as minimum or maximum. The PROMETHEE II method also uses a preference function $P_{j}(a, b)$ which depends on a pairwise difference between the evaluations $f_{j}(a)$ and $f_{j}(b)$ of alternatives $a$ and $b$ for criterion $i$. Six basic preference functions have been applied: usual criterion, quasi criterion, criterion with linear preference, level criterion, criterion with linear preference and indifference area, and Gaussian criterion. The main steps of the PROMETHEE II method are summarised below.

(i) Step 1: determination of each pair of possible decisions, and for each criterion the value of the preference degree.

(ii) Step 2 : determination for each pair of possible decisions, a global preference index.

(iii) Step 3 : determination of the outranking flows for each of the alternatives.

In this step, the positive outranking flow $\varphi^{+}\left(a_{i}\right)$ and the negative outranking flow 


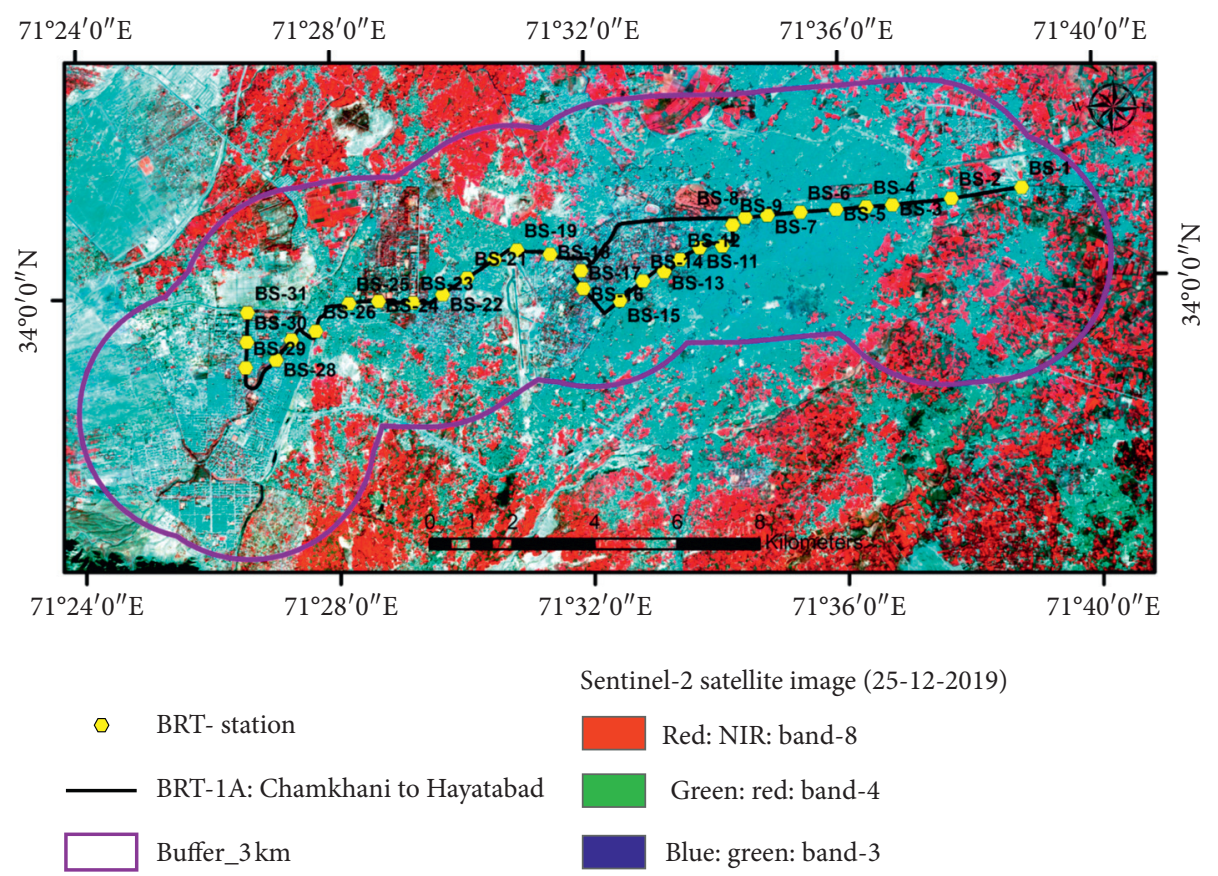

Figure 1: Peshawar City settlement overlaid with BRT station and route line.

$\varphi^{-}\left(a_{i}\right)$ are computed. The positive outranking flow expresses by how much each alternative is outranking all the others. The negative outranking flow expresses by how much each alternative is outranked by all the others.

(iv) Step 4: determination of the ranking of the criteria for each of the alternatives.

The alternatives are ranked according to the values of the net outranking flows. The net outranking flow $\varphi\left(a_{i}\right)$ of $a_{i}$ in the alternatives set $m$ of a possible decision is computed as the difference between $\varphi^{+}\left(a_{i}\right)$ and

$$
\varphi\left(a_{i}\right)=\varphi^{+}\left(a_{i}\right)-{ }^{-} \varphi\left(a_{i}\right)
$$

where $i=1, \ldots, m$ denotes number of alternatives.

For net outranking flow, the following conditions are valid:

$$
\begin{aligned}
\varphi\left(a_{i}\right) & \in[-1 ; 1], \\
\sum_{i=1}^{m} \varphi\left(a_{i}\right) & =0 .
\end{aligned}
$$

The highest value of the net outranking flow (formula (13)) shows the best decision.

\section{Results and Discussion}

4.1. Peshawar City: Main Characteristics. Peshawar is bound by Mohmand Agency towards Northwest, District Nowshera towards East, District Charsadda towards North, and
Khyber Agency towards West and South. The Afghan border is approximately $40 \mathrm{~km}$ to the West. Peshawar stands right at the entrance of the world-famous Khyber Pass and lies between $33^{\circ} 44$ and $34^{\circ} 15^{\prime}$ North latitudes and $71^{\circ} 22^{\prime}$ and $71^{\circ}$ $42^{\prime}$ East longitudes. The total area of the district is $1,216.17$ square kilometres and comprises of 92 Union Councils and 346 village/neighbourhoods councils, as shown in Figure 1.

The city of Peshawar is not only the provincial capital but also the mega city of the province. District Peshawar still has predominantly rural characteristics, where agriculture and allied sectors occupy around two third (64.42\%) of the land mass, followed by the vacant land (11\%), rural settlements/ villages (9\%), urban residentiary $(5.73 \%)$, water bodies (3.87\%), and roads/railway/terminals (3.34\%). The population of Peshawar is about 2 billion.

4.2. Passenger Survey Using a Questionnaire for Peshawar City. The self-structured (specially devised) questionnaire was filled in by travelers, as shown in Table 2 and Figures 2 and 3.

The following target groups were included in the survey: the business community, labourers, engineers, doctors, teachers, and students. 100 people were interviewed in each group. The total number of interviewees was 600 . The questionnaire contained 15 questions related to the BRT system, time, comfort, safety, special services, and stops. The answers indicated that the following were the most important criteria: time (78\% answer yes), reliability $(69 \%$ answer yes), comfort ( $88 \%$ answer yes), safety ( $84 \%$ answer yes), and fares (59\% of the passengers do not want fares to increase). These results were used as a basis for defining the criteria in the third step.

4.3. GIS Analysis for Peshawar. GIS analysis was done for the city of Peshawar, taking into account settlement area, 


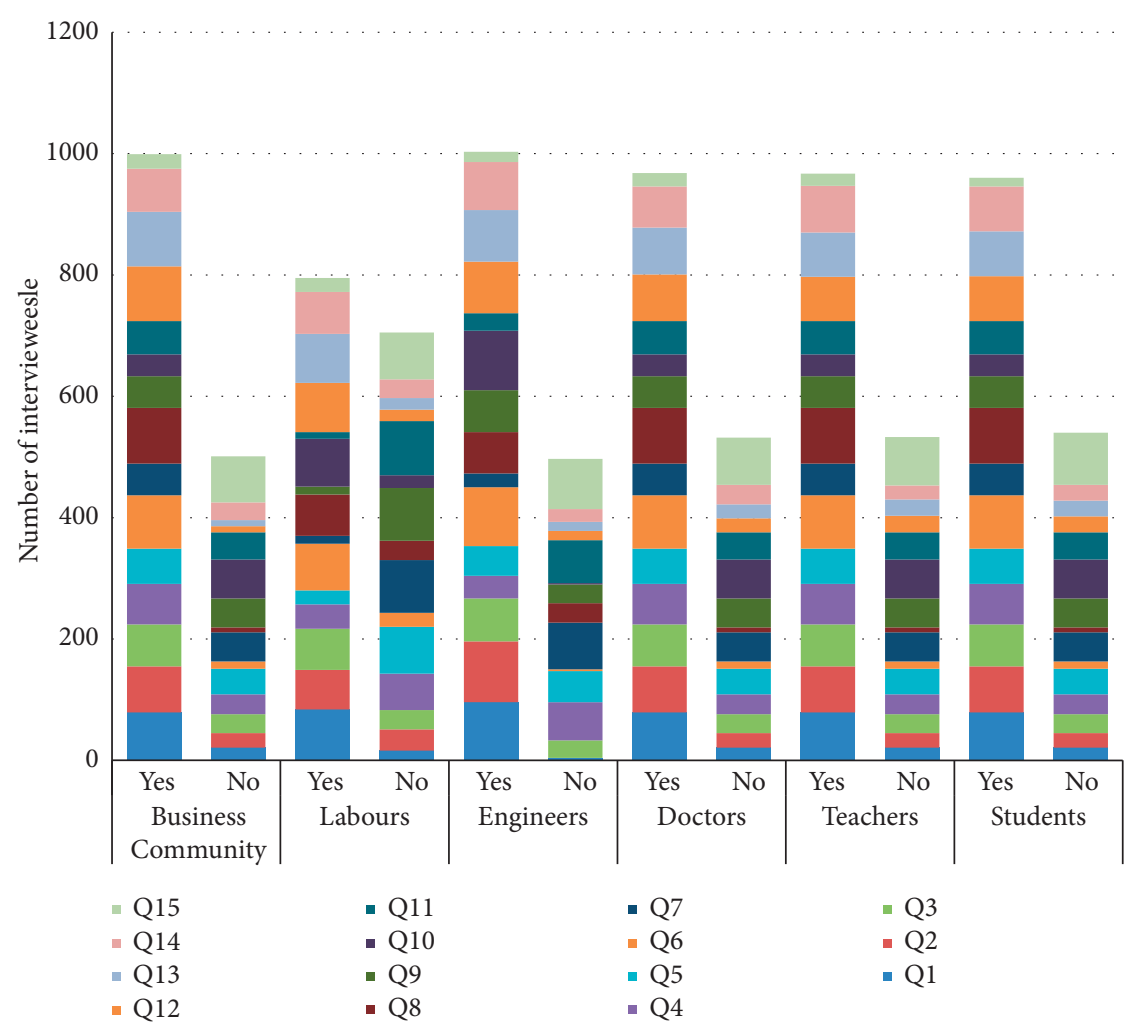

FIgURE 2: Comparison of the answers given by group interviewed.

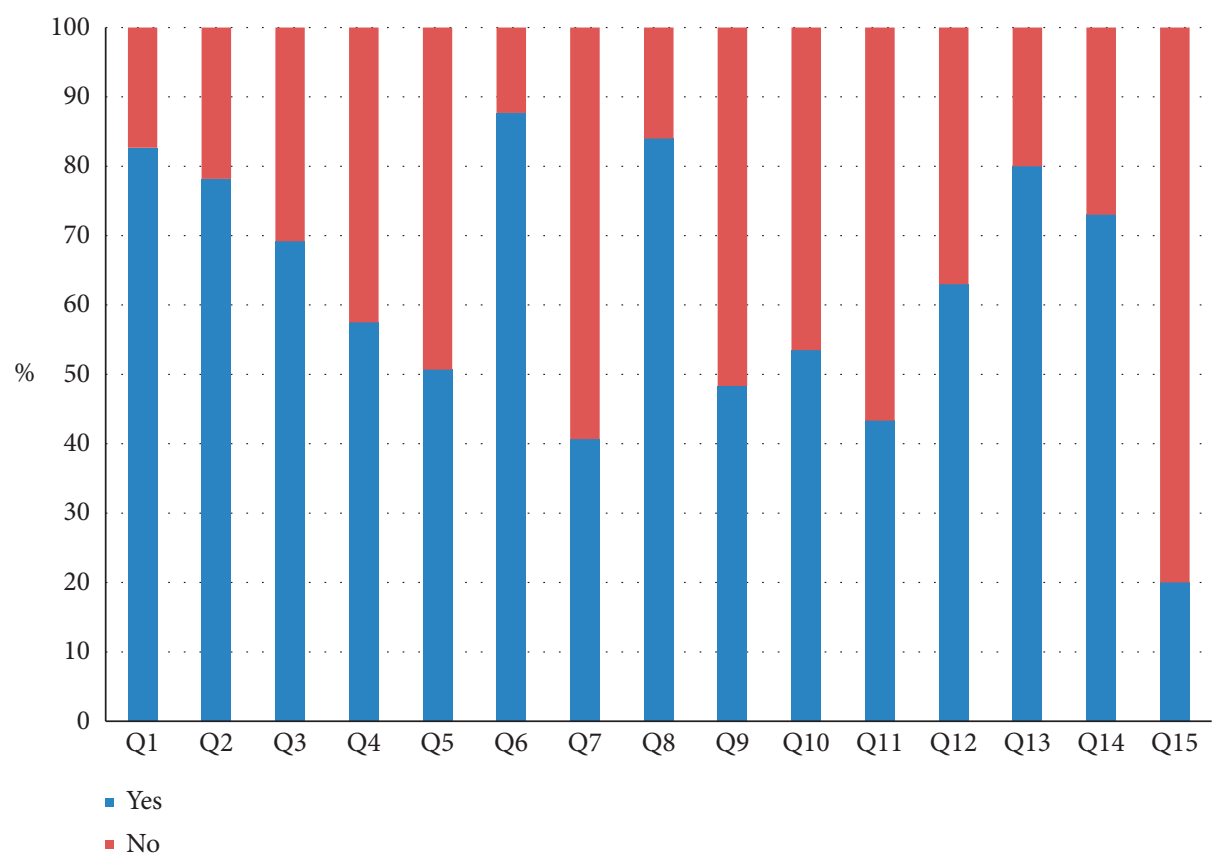

FIGURE 3: Comparison of total responses: positive and negative.

settlement density, vegetation, road line network with BRT station and locations, and line density functions figures generated while using road line data, as shown in Figures 1 and $4-7$.

In this settlement mapping procedure, we have used Sentinel-2 satellite images on 25th December 2019 and downloaded them from the USGS website (https:// earthexplorer.usgs.gov/). We have layer stacked the blue (B2), green (B3), red (B4), and near-infrared (B8) bands which retain 10-meter resolution [41, 42]. The supervised classifications were executed over the satellite data (Figure 1) to highlight the settlement and finally used to evaluate the 


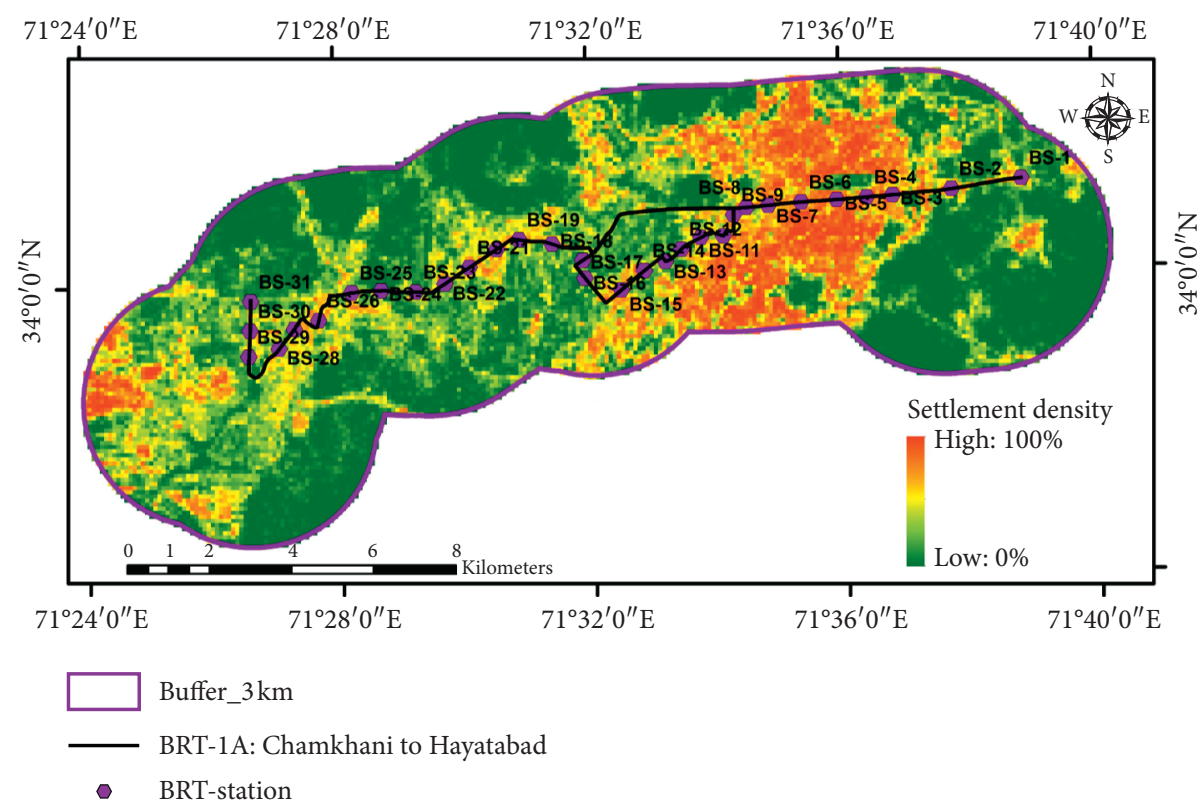

FIgURE 4: Settlement density across the BRT Station in Peshawar.

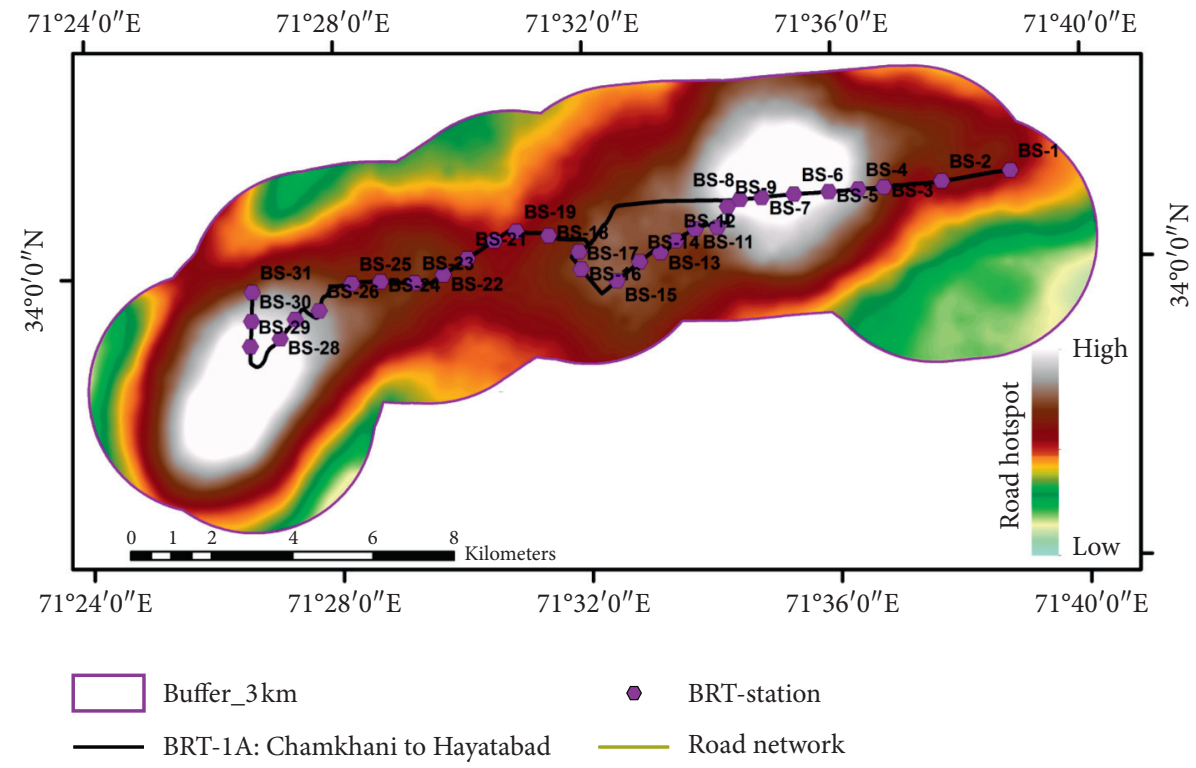

Figure 5: Settlement density from low to high for Peshawar City.

100 meter polygon vector grid. The mean settlement density percent (100\% means the grid is fully settlement whereas $0 \%$ means there is no settlement) was brought into the polygon vector grid, as shown in Figure 4. This polygon vector settlement density percent grid was converted to point file to create a settlement raster hotspot, as shown in Figure 5 by Kernel density (spatial analysis) which calculates magnitude per unit area. The road network data of Pakistan were downloaded from the website (https://download.geofabrik. de/asia.html). Road line data (Figure 6) were used to create a road raster hotspot map (Figure 7) using line density (spatial analysis) which calculates a magnitude per unit area from road polyline features. The priority of the 31 BRT-stations (point vector file) was evaluated based on the population proxy raster hotspot of road and settlement. Two columns were created in vector point file and the hotspot raster value was extracted and rescaled. The final priorities of all points were calculated as the average of the two column values for each BRT-station given in Figures 8 and 9.

The study analyzes the BRT stations on the basis of the settlement area and road density, through the ranking system adopted to determine the expected passenger demand on each station. The values received from road hotspot (Figure 7) and settlement hotspot (Figure 5) show that BS-6, BS-5, BS-7, BS-4, BS-8, BS-3, and BS-9 have higher ranking in terms of settlement, as shown in Figures 8 and 9 and 


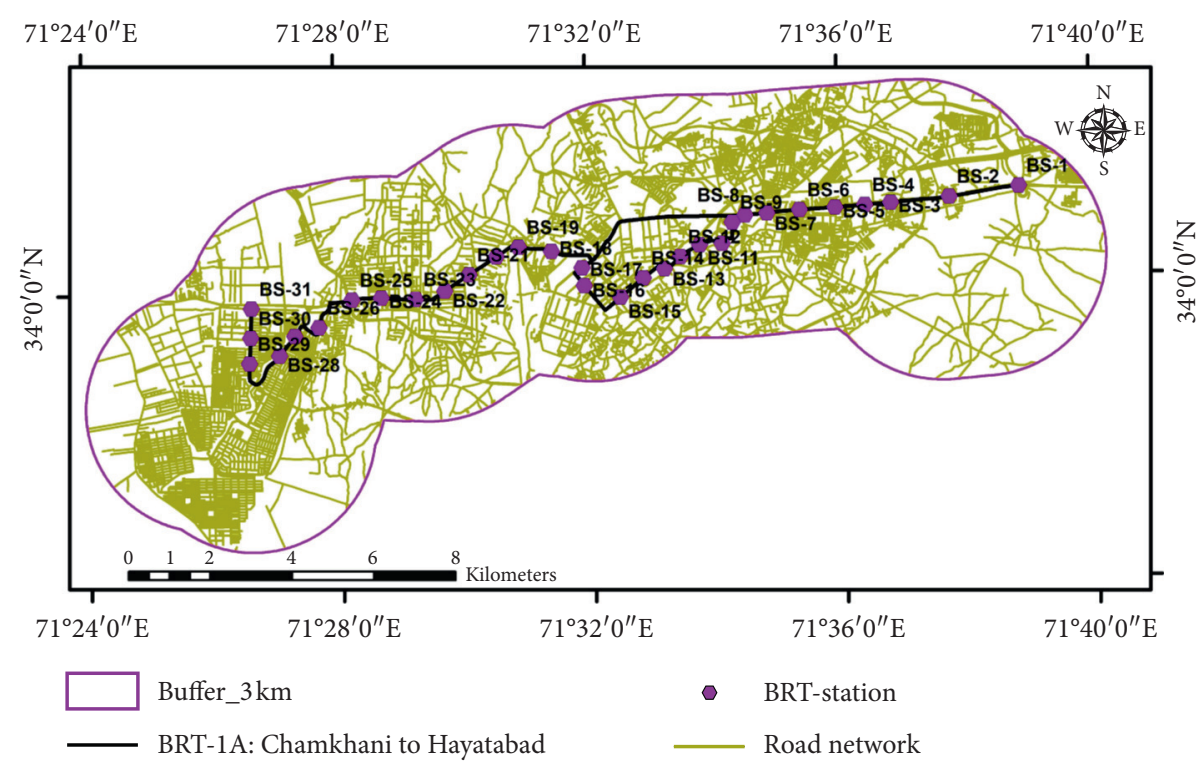

FIgURE 6: Road line network overlaid to BRT network.

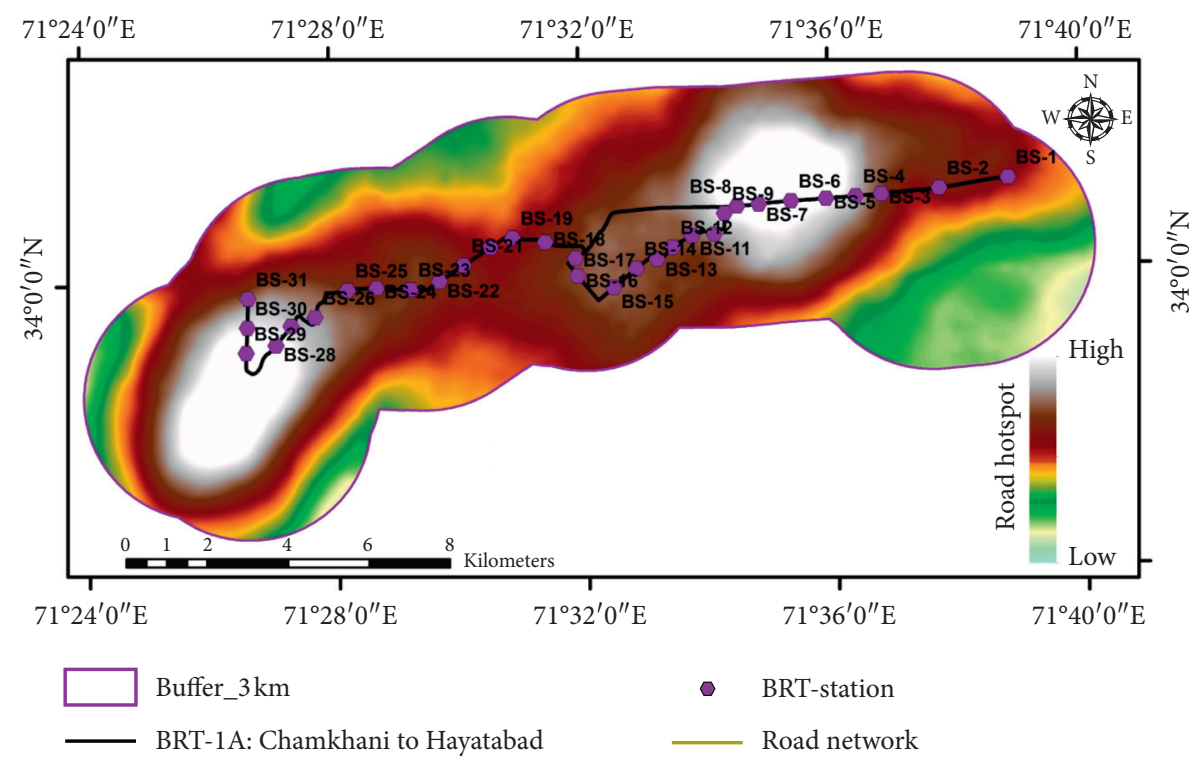

FIgURE 7: Road hotspot generated using line density function using road line data.

Table 3, while from Figures 1 and 4-7, it can be seen that those stations currently have a higher settlement and that there will be high passenger demand.

4.4. Determination of the Weighting of Criteria Using BWM. The group of seven experts gave an overall rating using the scale of Table 2, who are specialists with long experience in transport by academia ( 3 experts) and specialists by urban transport administration (4 experts). First, a pairwise comparison was made for the main criteria. The criterion strengths (IS) were selected by the experts as the best criteria and the criterion weaknesses (IW), respectively, as the worst criteria. Table 4 presents a pairwise comparison for the best and the worst criteria. The same procedure of assessment of the criteria was applied to the subcriteria of each main group. The criterion Security (S7) was determined as the best and the criterion dedicated infrastructure (S1) as the worst for the subcriteria of the main group costs. Table 5 shows the assessment of the experts.

The criterion low operating speed (W4) was defined as the best and small comfort (W6) as the worst for the subcriteria of the main group internal weaknesses (IW). Table 6 presents the assessment of the experts for this main group. The criterion environmental pollution (T3) was defined as the best and noise (T4) as the worst for the subcriteria of the main group external threats (ET). Table 7 presents the results. The criterion accessibility (O1) was defined as the best and the 


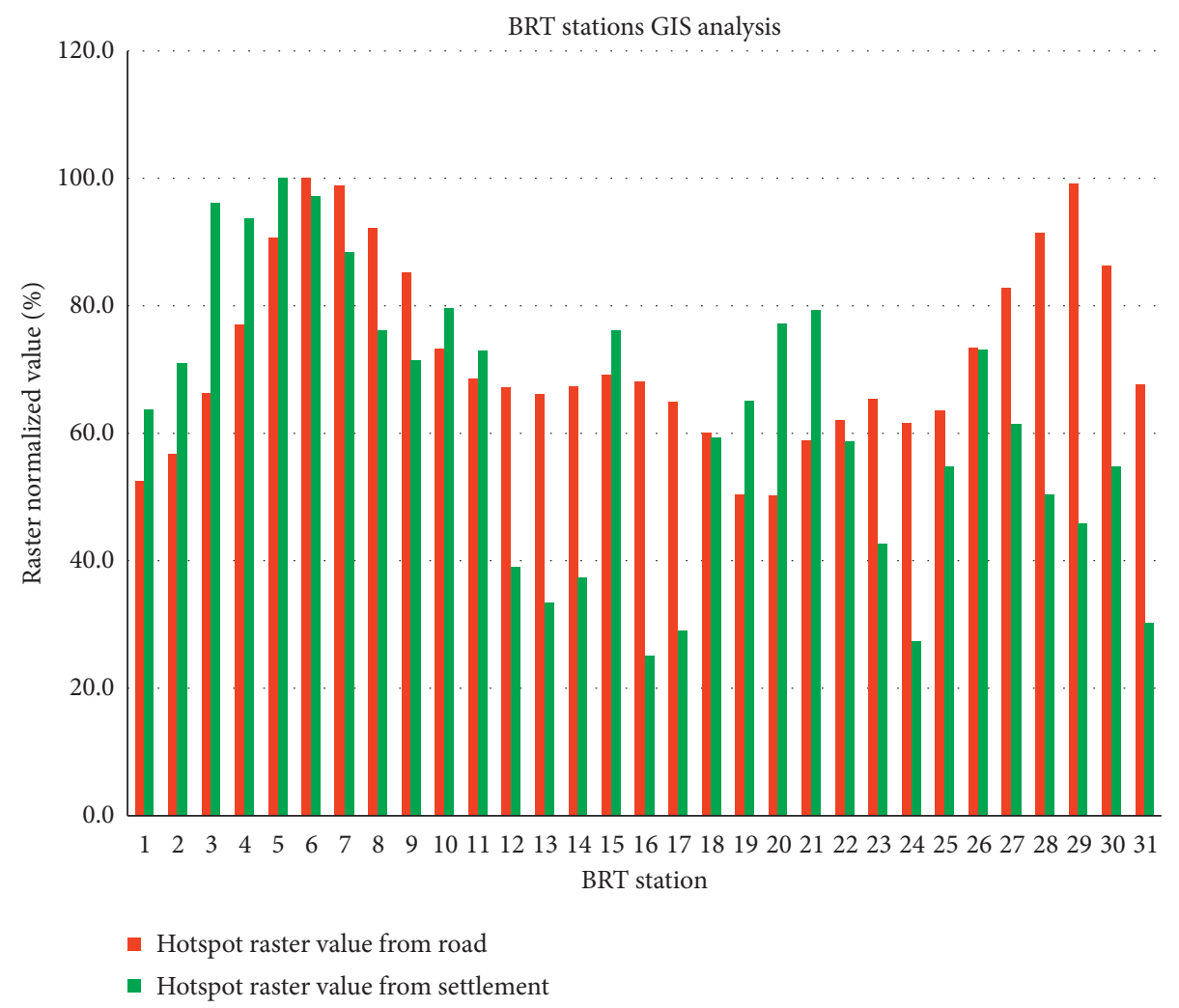

FIGURE 8: BRT stations' GIS analysis.

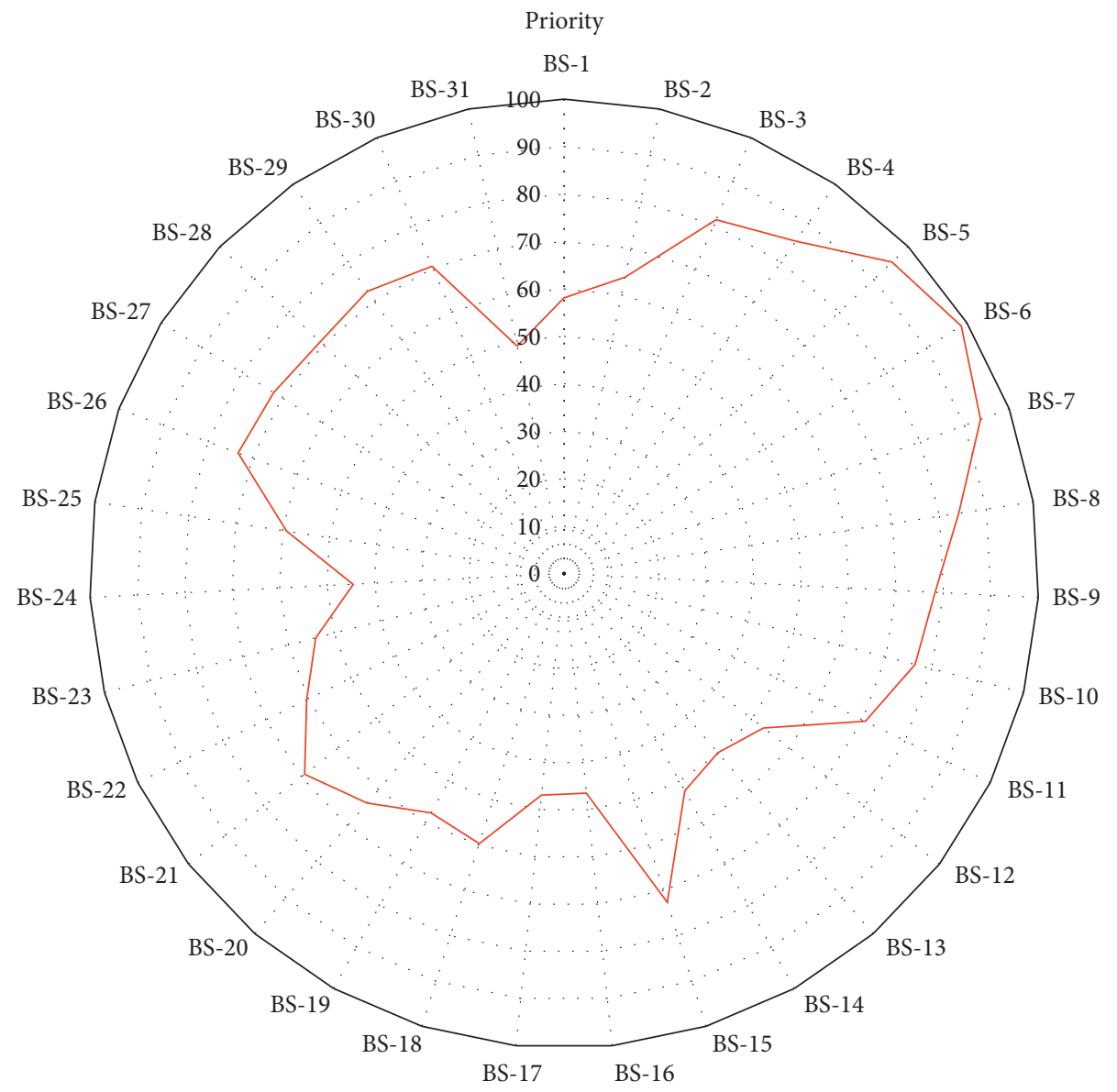


TABLE 3: BRT stations ranking system.

\begin{tabular}{|c|c|c|c|c|}
\hline BRT stations & Hotspot raster value from road & Hotspot raster value from settlement & Priority (average of settlement and road) & Ranking \\
\hline BS-1 & 52.6 & 63.7 & 58.1 & 22 \\
\hline BS-2 & 56.7 & 70.9 & 63.8 & 17 \\
\hline BS-3 & 66.2 & 96.2 & 81.2 & 6 \\
\hline BS-4 & 77.0 & 93.7 & 85.4 & 4 \\
\hline BS-5 & 90.6 & 100 & 95.3 & 2 \\
\hline BS-6 & 100.0 & 97. & 98.6 & 1 \\
\hline BS-7 & 98.8 & 97.2 & 93.6 & 3 \\
\hline BS-8 & 92.2 & 88.3 & 84.2 & 5 \\
\hline BS-9 & 85.2 & 76.1 & 78.3 & 7 \\
\hline BS-10 & 73.3 & 71.4 & 76.4 & 8 \\
\hline BS-11 & 68.5 & 72.9 & 70.7 & 14 \\
\hline BS- 12 & 67.2 & 39.1 & 53.1 & 25 \\
\hline BS-13 & 66.1 & 33.4 & 49.7 & 27 \\
\hline BS-14 & 67.4 & 37.4 & 52.4 & 26 \\
\hline BS-15 & 69.1 & 76.1 & 72.6 & 10 \\
\hline BS-16 & 68.1 & 25.0 & 46.5 & 30 \\
\hline BS-17 & 64.9 & 29.0 & 46.9 & 29 \\
\hline BS- 18 & 60.1 & 59.3 & 59.7 & 20 \\
\hline BS-19 & 50.4 & 65.0 & 57.7 & 23 \\
\hline BS-20 & 50.2 & 77.2 & 63.7 & 18 \\
\hline BS-21 & 58.8 & 79.4 & 69.1 & 16 \\
\hline BS-22 & 62.1 & 58.7 & 60.4 & 19 \\
\hline BS-23 & 65.4 & 42.7 & 54.0 & 24 \\
\hline BS-24 & 61.5 & 27.4 & 44.5 & 31 \\
\hline BS-25 & 63.5 & 54.7 & 59.1 & 21 \\
\hline BS-26 & 73.4 & 73.1 & 73.2 & 9 \\
\hline BS-27 & 82.8 & 61.4 & 72.1 & 12 \\
\hline BS-28 & 91.4 & 50.3 & 70.9 & 13 \\
\hline BS-29 & 99.2 & 45.9 & 72.5 & 11 \\
\hline BS-30 & 86.3 & 54.7 & 70.5 & 15 \\
\hline BS-31 & 67.7 & 30.2 & 49.0 & 28 \\
\hline
\end{tabular}

TABLE 4: Main criteria-pairwise comparison vector.

\begin{tabular}{lccccc}
\hline Criteria & Best/worst criteria & Strengths (IS) & Weaknesses (IW) & Opportunities (EO) & Threats (ET) \\
\hline Best to others & Best: strengths (IS) & 1 & 6 & 1 & 3 \\
Others to the worst & Worst: weaknesses (IW) & 7 & 1 & 4 & 2 \\
\hline
\end{tabular}

criterion possibility of modernization of the infrastructure (O4) as the worst for the subcriteria of the main group external opportunities (EO). Table 8 presents the results.

To solve the linear optimization given by formulas (3)-(10), SOLVER in EXCEL was used. Table 9 presents the results. It can be seen that the weightings of the main criteria internal strengths (IS) and internal weaknesses (IW) are the greatest. The local weightings for each group and the global weightings of the criteria are determined. The local weightings show the weighting of each subcriterion in the respective group of the main criterion. The global weightings rank all the subcriteria taking into account the weightings of the main criteria.

The values of consistency $\xi^{*}$ for the main criteria and subcriteria are shown in Table 10. It can be seen that these values are close to zero, which shows a high degree of consistency.

4.5. Ranking the Alternative Modes of Transportation. The PROMETHEE Method has been applied to choose the best alternatives. Table 11 presents the values of the subcriteria and the type of optimization for each criterion.
The visual PROMETHEE software was used [43]. Figure 10 presents the results in two parts. The first part shows the ranking according to net outranking flows, and the second part presents the values of the subcriteria. It can be seen that the best alternative is a BRT with 5 new stops. The main important criteria over 5\% are small movement interval: S4 (6\%), security: S7 (13\%), reliability: S8 (8\%), accessibility: O1 (15\%), possibility of special services: $\mathrm{O} 2(5 \%)$, possibility of inclusion of insurance in the travel tariff: $\mathrm{O} 3(8 \%)$, possibility of modernization of the infrastructure: $\mathrm{O} 4$ (7\%), and environmental pollution: T3 (5\%). The results are similar to those given by the answers in the questionnaire, where passengers indicated that the most important criteria are reliability, comfort, safety, and fares.

Figure 10 shows that the main important criteria for strengths' group are the security and the reliability. The criteria that are more important in the weaknesses' group are the operating speed and the time of travel. The criteria accessibility and the possibility of inclusion of insurance in the travel tariff are more important for the opportunities group. The criterion environmental pollution is the more important for the threats' group. 
TABLE 5: Internal strengths (IS)-pairwise comparison vector.

\begin{tabular}{|c|c|c|c|c|c|c|c|c|c|}
\hline Criteria & Best/worst criteria & S1 & S2 & S3 & S4 & S5 & S6 & S7 & S8 \\
\hline Best to others & Best: security (S7) & 7 & 6 & 4 & 3 & 5 & 5 & 1 & 2 \\
\hline Others to the worst & Worst: dedicated infrastructure (S1) & 1 & 3 & 3 & 7 & 5 & 5 & 7 & 6 \\
\hline
\end{tabular}

TABLE 6: Internal weaknesses (IW)-pairwise comparison vector.

\begin{tabular}{lccccccc}
\hline Criteria & Best/worst criteria & W1 & W2 & W3 & W4 & W5 & W6 \\
\hline Best to others & Best: low operating speed (W4) & 4 & 3 & 5 & 1 & 1 & 3 \\
Others to the worst & Worst: small comfort (W6) & 4 & 3 & 1 & 5 & 4 & 3 \\
\hline
\end{tabular}

TABLE 7: External threats (ET)-pairwise comparison vector.

\begin{tabular}{|c|c|c|c|c|c|c|c|}
\hline Criteria & Best/worst criteria & $\mathrm{T} 1$ & $\mathrm{~T} 2$ & $\mathrm{~T} 3$ & $\mathrm{~T} 4$ & T5 & T6 \\
\hline Best to others & Best-environmental pollution (T3) & 3 & 2 & 1 & 3 & 2 & 2 \\
\hline Others to the worst & Worst: noise (T4) & 3 & 2 & 4 & 1 & 4 & 3 \\
\hline
\end{tabular}

TABLE 8: External opportunities (EO)-pairwise comparison vector.

\begin{tabular}{|c|c|c|c|c|c|}
\hline Criteria & Best/Worst criteria & $\mathrm{O} 1$ & $\mathrm{O} 2$ & O3 & $\mathrm{O} 4$ \\
\hline Best to others & Best: accessibility (O1) & 1 & 3 & 2 & 2 \\
\hline Others to the worst & Worst: possibility of modernization of the infrastructure (O4) & 3 & 1 & 2 & 1 \\
\hline
\end{tabular}

TABLE 9: Weights of main criteria and subcriteria.

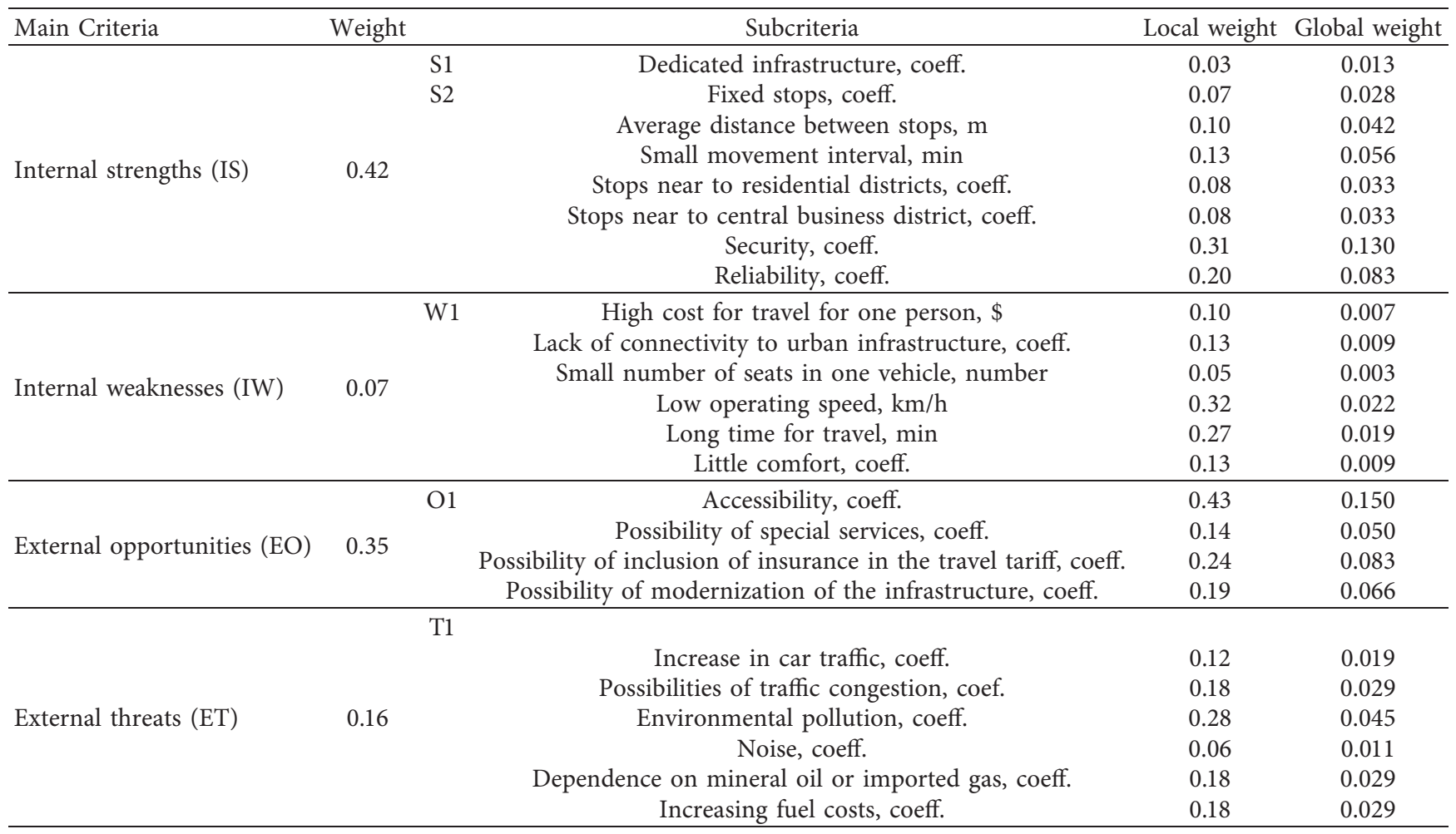

It could be seen that the BRT service is the more suitable alternative. The first position has the BRT alternative with 5 new stops. The introduction of the proposed new stops will contribute to the improvement of the transport service in the city. The second position has the BRT system in current situation. The both positions show that the BRT is the best 
TABLE 10: Values of consistency for main criteria and subcriteria.

\begin{tabular}{lcccrr}
\hline Criteria & Main criteria & IS & IW & EO & ET \\
\hline$\xi^{*}$ & 0.069 & 0.089 & 0.085 & 0.047 & 0.079 \\
\hline
\end{tabular}

TABLE 11: Values of the criteria (type of optimization).

\begin{tabular}{|c|c|c|c|c|c|c|c|c|}
\hline \multirow{2}{*}{ Criteria } & & \multicolumn{6}{|c|}{ Alternatives } & \multirow{2}{*}{ Type of optimization } \\
\hline & & A1 & $\mathrm{A} 2$ & A3 & A4 & A5 & A6 & \\
\hline \multicolumn{9}{|c|}{ Internal strengths (IS) } \\
\hline S1 & Dedicated infrastructure, coeff. & 0 & 0 & 0 & 0 & 1 & 1 & Max \\
\hline S2 & Fixed stops, coeff. & 0 & 0 & 0 & 0 & 1 & 1 & Max \\
\hline S3 & Average distance between stops, $\mathrm{m}$ & 400 & 400 & 400 & 400 & 800 & 600 & Min \\
\hline S4 & Small movement interval, min & 10 & 3 & 3 & 7 & 3 & 3 & Min \\
\hline S5 & Stops near to residential districts, coeff. & 1 & 1 & 1 & 1 & 0 & 1 & $\operatorname{Max}$ \\
\hline S6 & Stops near to the central business district, coeff. & 1 & 1 & 1 & 1 & 0 & 1 & $\operatorname{Max}$ \\
\hline S7 & Security, coeff. & 0 & 0 & 0 & 1 & 1 & 1 & $\operatorname{Max}$ \\
\hline S8 & Reliability, coeff. & 0 & 0 & 0 & 1 & 1 & 1 & $\operatorname{Max}$ \\
\hline \multicolumn{9}{|c|}{ Internal weaknesses (IW) } \\
\hline W1 & High cost for travel for one person, $\$$ & 0.2 & 0.3 & 0.4 & 2 & 0.2 & 0.2 & Min \\
\hline W2 & Lack of connectivity to urban infrastructure, coeff. & 0 & 0 & 0 & 0 & 1 & 0 & Min \\
\hline W3 & Small number of seats in one vehicle, number & 35 & 15 & 5 & 4 & 60 & 60 & $\operatorname{Max}$ \\
\hline W4 & Low operating speed, $\mathrm{km} / \mathrm{h}$ & 18 & 32 & 40 & 50 & 55 & 55 & Max \\
\hline W5 & Long-time of travel, min & 109 & 72 & 60 & 47 & 51 & 53 & Min \\
\hline W6 & Low comfort, coeff. & 1 & 1 & 1 & 0 & 0 & 0 & Min \\
\hline \multicolumn{9}{|c|}{ External opportunities (EO) } \\
\hline $\mathrm{O} 1$ & Accessibility, coeff. & 0 & 0 & 0 & 1 & 1 & 1 & $\operatorname{Max}$ \\
\hline $\mathrm{O} 2$ & Possibility of special services, coeff. & 0 & 0 & 0 & 1 & 1 & 1 & Max \\
\hline $\mathrm{O} 3$ & $\begin{array}{c}\text { Possibility of inclusion of insurance in the travel tariff, } \\
\text { coeff. }\end{array}$ & 0 & 0 & 0 & 1 & 1 & 1 & $\operatorname{Max}$ \\
\hline $\mathrm{O} 4$ & $\begin{array}{l}\text { Possibility of modernization of the infrastructure, } \\
\text { coeff. }\end{array}$ & 0 & 0 & 0 & 0 & 1 & 1 & $\operatorname{Max}$ \\
\hline \multicolumn{9}{|c|}{ External threats (ET) } \\
\hline $\mathrm{T} 1$ & Increase in car traffic, coeff. & 1 & 1 & 1 & 1 & 0 & 0 & Min \\
\hline $\mathrm{T} 2$ & Possibilities of traffic congestion, coeff. & 1 & 1 & 1 & 1 & 0 & 0 & Min \\
\hline T3 & Environmental pollution, coeff. & 1 & 1 & 1 & 1 & 0 & 0 & Min \\
\hline $\mathrm{T} 4$ & Noise, coeff. & 1 & 1 & 1 & 1 & 0 & 0 & Min \\
\hline $\mathrm{T} 5$ & Dependence on mineral oil or imported gas, coeff. & 1 & 1 & 1 & 1 & 0 & 0 & Min \\
\hline T6 & Increasing fuel costs, coeff. & 1 & 0 & 0 & 0 & 0 & 0 & Min \\
\hline
\end{tabular}
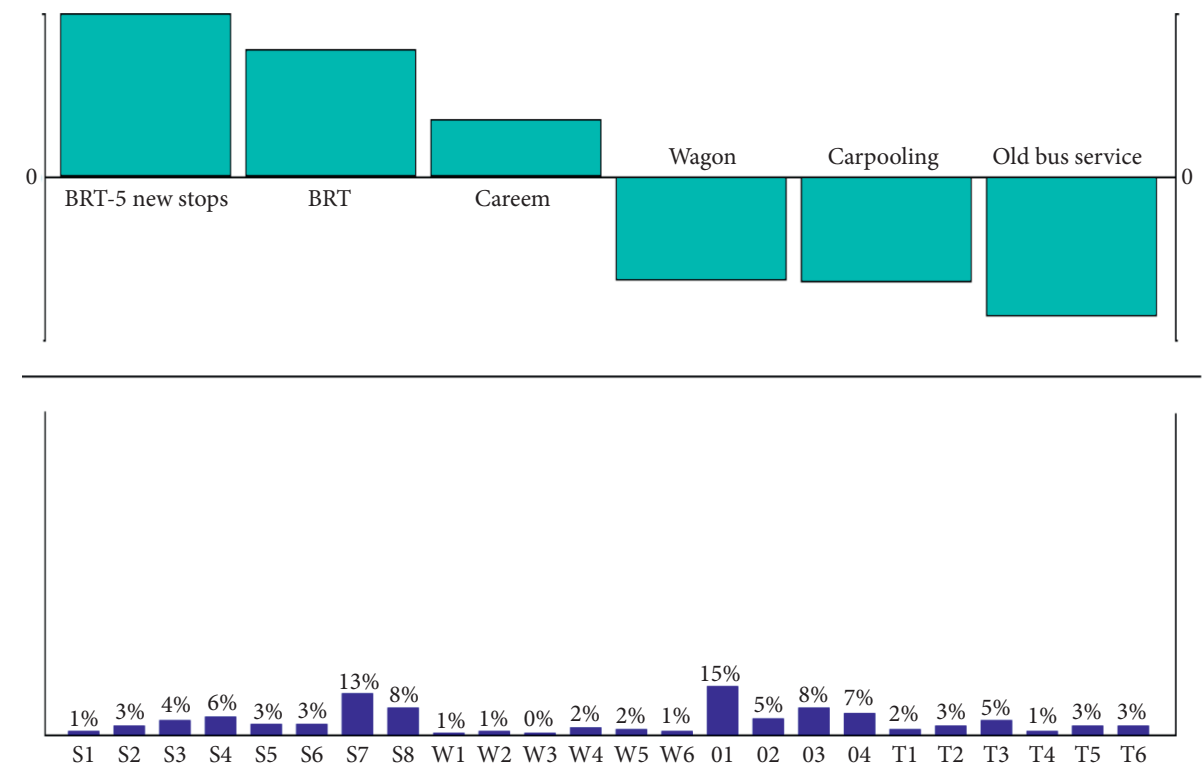

FIGURE 10: Range of alternative transport modes and weightings of criteria in the visual PROMETHEE software. 
TABLE 12: Stability intervals.

\begin{tabular}{|c|c|c|c|c|c|c|c|c|c|c|c|}
\hline Criterion & $\begin{array}{c}\text { Lower } \\
\text { limit (\%) }\end{array}$ & $\begin{array}{c}\text { Upper } \\
\text { limit (\%) }\end{array}$ & Criterion & $\begin{array}{c}\text { Lower } \\
\text { limit (\%) }\end{array}$ & $\begin{array}{c}\text { Upper } \\
\text { limit (\%) }\end{array}$ & Criterion & $\begin{array}{c}\text { Lower } \\
\text { limit (\%) }\end{array}$ & $\begin{array}{c}\text { Upper } \\
\text { limit (\%) }\end{array}$ & Criterion & $\begin{array}{c}\text { Lower } \\
\text { limit (\%) }\end{array}$ & $\begin{array}{c}\text { Upper } \\
\text { limit (\%) }\end{array}$ \\
\hline S1 & 0 & 100 & W1 & 0 & 100 & $\mathrm{O} 1$ & 0 & 100 & $\mathrm{~T} 1$ & 0 & 100 \\
\hline S2 & 0 & 100 & W2 & 0 & 100 & $\mathrm{O} 2$ & 0 & 100 & $\mathrm{~T} 2$ & 0 & 100 \\
\hline S3 & 0 & 28.63 & W3 & 0 & 100 & $\mathrm{O} 3$ & 0 & 100 & $\mathrm{~T} 3$ & 0 & 100 \\
\hline S3 & 0 & 100 & W3 & 0 & 100 & $\mathrm{O} 4$ & 0 & 100 & $\mathrm{~T} 3$ & 0 & 100 \\
\hline S5 & 0 & 100 & W5 & 0 & 46.14 & & & & $\mathrm{~T} 5$ & 0 & 100 \\
\hline S6 & 0 & 100 & W6 & 0 & 100 & & & & T6 & 0 & 100 \\
\hline S7 & 0 & 100 & & & & & & & & & \\
\hline S8 & 0 & 100 & & & & & & & & & \\
\hline
\end{tabular}

mode of transport for Peshawar city. These results coincide with the answers in the questioners, where passengers prefer BRT mode of transport. The ranking shows that the service by old bus is the worst mode of travel. In current situation, this mode is used by people who do not have other options. The service Careem/Uber is ranked third. This transport mode is assessed also as more attractive since carpooling, wagons, and old buses prices are almost the same as a local taxi, and it offers more security, reliability, and privacy. The wagon, carpooling, and old buses have negative outranking flows according Figure 10. The wagon service is the second mode to travel in Peshawar city and is considered better than the old bus service and the carpooling. In current situation, carpooling is a local service, which operates on specified routes, where 3 to 4 passengers share their ride.

The stability intervals of changing the weightings of the criteria in which the optimal solution is retained are shown in Table 12. Most criteria have wide limits of variation. The criteria average distance between stops (S3) and long time for travel (W5) have relatively small limits of variation. This means that both criteria affect the ranking. The criterion average distance between stops has a stronger influence, as its limits of change are smaller compared to the criterion long time for travel.

\section{Conclusion}

This research uses a combination of GIS Analysis, SWOT Analysis, BWM method, and PROMETHEE II method to determine the most suitable mode of transport between predetermined alternatives. A methodology that combines SWOT analysis with BWM and PROMETHEE methods is the main contribution of this paper. Using a survey consisting of 15 questions related to the BRT system, six groups and 600 participants demonstrated that time, comfort, safety, special services, and stops are the main factors related to transport preference. SWOT analysis is used to determine the main factors such as strengths, weaknesses, opportunities, and threats for the selection of the best mode of transport for passenger city transport. The subcriteria for each main criterion of each SWOT group are defined. The proposed criteria are important for transport companies and passenger requirements. The weightings of the main SWOT criteria and subcriteria have been determined by applying the BWM method. It is found that the main importance of the SWOT group is that it has the strengths of group criteria
(0.42) and opportunities (0.35). It is found that the main important features that over $5 \%$ of all the subcriteria have are a small movement interval: S4 (6\%), security: S7 (13\%), reliability: S8 (8\%), accessibility: O1 (15\%), the possibility of special services: O2 (5\%), the possibility of including insurance in the travel tariff: $\mathrm{O} 3(8 \%)$, the possibility of modernization of the infrastructure: $\mathrm{O} 4$ (7\%), and environmental pollution: T3 (5\%). Five alternatives for transportation in Peshawar have been compared. GIS analysis has been applied to investigate the stops for the BRT system. Five new stops are proposed. The study produces a ranking of alternative modes of transportation for Peshawar and shows that the BRT system with five new stops is the best alternative. The application of the proposed transport plan with five new stops for the BRT system will increase the satisfaction of the transport needs of the urban passengers. This research proves that the Peshawar city has a need to reorganize public transport by introducing modern fast and convenient modes transport, such as BRT, and also to improve the transport services by introducing the new stops for BRT system.

The originality of this research consists in integration of a strategic planning technique SWOT analysis, GIS analysis, and multicriteria analysis in complete methodology to evaluate travelers' modes priority. The methodology used in this research can be applied to evaluate different transport alternatives for transport networks worldwide. The methodology developed in this study could be used to investigate modes of transportation in other cities worldwide.

\section{Data Availability}

The data used to support the findings of the study are cited in references within the article.

\section{Conflicts of Interest}

The authors declare no conflicts of interest.

\section{References}

[1] A. Farooq, M. Xie, S. Stoilova et al., "Transportation planning through GIS and multicriteria analysis: case study of beijing and XiongAn," Journal of Advanced Transportation, vol. 2018, Article ID 2696037, 16 pages, 2018.

[2] D. Nalmpantis, "Evaluation of innovative ideas for public transport proposed by citizens using multi-criteria decision 
analysis (MCDA)," European Transport Research Review, vol. 22, 2019.

[3] A. Farooq, A. Javaid, and A. Karl, "Peshawar local public transport strategy and organization," International Journal of Engineering Development and Research, vol. 3, no. 4, 2015.

[4] Z. Li, D. A. Hensher, and J. M. Rose, "Willingness to pay for travel time reliability in passenger transport: a review and some new empirical evidence,", Transportation Research Part E: Logistics and Transportation Review, vol. 46, no. 3, pp. 384-403, 2010.

[5] M. Hilber, "The importance of safety and security in public transportation systems," Transign LLC. Retrieved from https://transignllc.com/the-importance-of-safety-andsecurity-in-public-transportation-systems, 2019.

[6] T. B. Joewono and H. Kubota, "Safety and security improvement IN public transportation based ON public perception IN developing countries," IATSS Research, vol. 30, no. 1 , pp. 86-100, 2006.

[7] M. Batarce, J. C. Muñoz, J. d. Ortúza, S. Raveau, C. Mojica, and R. A. Ríos, Evaluation of Passenger Comfort in Bus Rapid Transit Systems, Inter-American Development Bank, Washington, DC, USA, 2015.

[8] M. Laberinti, A. Mahmoud, and A. Abo-Sinna, "A novel approach for fully intuitionistic fuzzy multi-objective fractional transportation problem," Alexandria Engineering Journal, vol. 60, no. 1, pp. 1447-1463, 2021.

[9] N. Koohathongsumrit and W. Meethom, "An integrated approach of fuzzy risk assessment model and data envelopment analysis for route selection in multimodal transportation networks, expert systems with applications," Expert Systems with Applications, vol. 171, no. 1, Article ID 114342, 2020.

[10] H. Mokhtari and A. Hasani, "A multi-objective model for cleaner production-transportation planning in manufacturing plants via fuzzy goal programming," Journal of Manufacturing Systems, vol. 44, pp. 230-242, 2017.

[11] J. Rezaei, "Best-worst multi-criteria decision-making method," Omega, vol. 53, pp. 49-57, 2015.

[12] J. Rezaei, "Best-worst multi-criteria decision-making method: some properties and a linear model," Omega, vol. 64, pp. 126-130, 2016.

[13] P. Pam, "Pakistan: peshawar sustainable bus rapid transit corridor project (RRP PAK 48289)," Project Administration Manual (PAM) Retrieved from https://www.adb.org/sites/ default/files/project-documents/48289/48289-002-pam-en. pdf, 2017.

[14] J. Rezaei, T. Nispeling, J. Sarkis, and L. Tavasszy, “A supplier selection life cycle approach integrating traditional and environmental criteria using the best worst method," Journal of Cleaner Production, vol. 135, pp. 577-588, 2016.

[15] J. Rezaei, J. Wang, and L. Tavasszy, "Linking supplier development to supplier segmentation using Best Worst Method," Expert Systems with Applications, vol. 42, no. 23, pp. 9152-9164, 2015.

[16] X. You, T. Chen, and Q. Yang, “Approach to multi-criteria group decision-making problems based on the best-worstmethod and electre Method," Mathematics, Computer Science, vol. 8, no. 9, p. 95, 2016.

[17] H. Gupta, "Evaluating service quality of airline industry using hybrid best worst method and VIKOR," Journal of Air Transport Management, vol. 68, pp. 35-47, 2018.

[18] S. Stoilova, "Evaluation the efficiency of urban transport modes using multi-criteria analysis," in . Proceedings of the International Conference 23rd International Scientific
Conference on Transport Means, pp. 35-47, Kaunas, Lithuania, May 2019.

[19] A. Görener, K. Toker, and K. Uluçay, "Application of combined SWOT and AHP: a case study for a manufacturing firm," Procedia-Social and Behavioral Sciences, vol. 58, pp. 1525-1534, 2012.

[20] S. D. Stoilova and S. V. Martinov, "Selecting a location for establishing a rail-road intermodal terminal by using a hybrid SWOT/MCDM model," IOP Conference Series: Materials Science and Engineering, vol. 618, Article ID 012060, 2019.

[21] J.-P. Brans and B. Mareschal, "PROMETHEE methods," International Series in Operations Research \& Management Science, vol. 78, pp. 163-186, 2005.

[22] M. Behzadian, R. B. Kazemzadeh, A. Albadvi, and M. Aghdasi, "PROMETHEE: a comprehensive literature review on methodologies and applications," European Journal of Operational Research, vol. 200, no. 1, pp. 198-215, 2010.

[23] L. Gigovic, S. Drobnjak, and D. Pamucar, "The application of the hybrid GIS spatial multi-criteria decision analysis best-worst methodology for landslide susceptibility mapping," Journal of Geo-Information, vol. 8, no. 79, 2019.

[24] D. Pamucar, L. Gigovic, Z. Baji, and M. Janoševic, "Location selection for wind farms using GIS multi-criteria hybrid model: an approach based on fuzzy and rough numbers," Sustainability, vol. 9, no. 8, pp. 1-1315, 2017.

[25] N. R. Rahman, M. A. Chowdhury, A. Firoze, and M. R. Rahman, "Fusion of BWM and AHP MCDM methods to choose the most suitable secondary school for an individual in the context of Bangladesh," Vietnam Journal of Computer Science, vol. 6, no. 3, pp. 311-328, 2019.

[26] A. Yan, M. Xie, S. Stoilova, and E. J. Williams, The Application of Smart Urban Mobility Strategies and Initiatives: Application to Beijing, European Transport $\backslash$ Trasporti Europei, Beijing, China, 2019.

[27] Urban, "Urban transport pre-feasibility study Peshawar, Pakistan. Managing the cities in Asia," Retrieved from http:// urbanpolicyunit.gkp.pk/wp-content/uploads/2017/05/ Peshawar-FINAL-REPORT-23052014.pdf, 2014.

[28] A. H. Bacha, "Worst gridlocks in peshawar as people leave for hometowns the dawn news," Retrieved from https://www. dawn.com/news/1122105, 2014.

[29] S. Khattak, "Urbanscape: a farewell to wagons. The dawn news," Retrieved https://www.dawn.com/news/1496631, 2019.

[30] Careem, "Careem," Retrieved from https://www.careem.com/ en-ae/safety-and-security/, 2019.

[31] A. Bonnier, M. Finné, and E. Weiberg, "Examining land-use through GIS-based Kernel density estimation: a re-evaluation of legacy data from the berbati-limnes survey," Journal of Field Archaeology, vol. 44, no. 2, pp. 70-83, 2019.

[32] A. Casarotto, J. Pelgrom, and T. D. Stek, "A systematic GISbased analysis of settlement developments in the landscape of venusia in the hellenistic-roman period," Archaeological and Anthropological Sciences, vol. 11, no. 2, pp. 735-753, 2019.

[33] M. Altaweel, "Density mapping with GIS," Spatial Analysis. Retrieved from https://www.gislounge.com/density-mapping/, 2017.

[34] E. Lee and P. Oduor, "Using multi-attribute decision factors for a modified all-or-nothing traffic assignment," ISPRS International Journal of Geo-Information, vol. 4, no. 2, pp. 883-899, 2015.

[35] M. Zuidgeest, M. Brussel, and M. Van Maarseveen, "GIS for sustainable urban transport," ISPRS International Journal of Geo-Information, vol. 4, no. 4, pp. 2583-2585, 2015. 
[36] Z. M. dan, T. Guoan, S. W. zhong, and L. Y. Mei, “A GISbased research on the distribution of rural settlements in Yulin of northern Shaanxi," Journal of Geographical Sciences, vol. 12, pp. 171-176, 2002.

[37] B. Y.-M. Wong, G. Faulkner, and R. Buliung, "GIS measured environmental correlates of active school transport: a systematic review of 14 studies," International Journal of Behavioral Nutrition and Physical Activity, vol. 8, no. 1, p. 39, 2011.

[38] W. Ji, Y. Wang, D. Zhuang et al., "Spatial and temporal distribution of expressway and its relationships to land cover and population: a case study of Beijing, China," Transportation Research Part D: Transport and Environment, vol. 32, pp. 86-96, 2014.

[39] P. N. Dadhich and S. Hanaoka, "Spatial investigation of the temporal urban form to assess impact on transit services and public transportation access," Geo-spatial Information Science, vol. 15, no. 3, pp. 187-197, 2012.

[40] H. M. Taki and M. Z. Lubis, "Modeling accessibility of community facilities using GIS: case study of Depok city, Indonesia," Journal of Applied Geospatial Information, vol. 1, no. 2, pp. 36-43, 2017.

[41] A. M. Abdi, "Land cover and land use classification performance of machine learning algorithms in a boreal landscape using Sentinel-2 data," GIScience \& Remote Sensing, vol. 57, no. 1, pp. 1-20, 2019.

[42] M. Drusch, U. Del Bello, S. Carlier et al., "Sentinel-2: ESA's optical high-resolution mission for GMES operational services," Remote Sensing of Environment, vol. 120, pp. 25-36, 2011.

[43] Promethee, "Visual PROMETHEE software," Retrieved from https://www.promethee-gaia.net/, 2020. 